\section{PREVENTIVE MEDICINE AND PUBLIC HEALTH}

By Fred Grundy, M.D., M.R.C.S., D.P.H. Pp. 299, illustrated. Luton: The Leagrave Press. I93 I. I 8s.

There was a time when the Medical Officer of Health was supposed to concern himself chiefly, if not entirely, with drains and sewers, dustbins and infectious fevers. It is still at his peril-and that of the community - that he fails to maintain a lively interest in such matters; and in relation to infectious diseases his vigilance must still be unsleeping. It is true that the changes of a century have relieved him of many demands in regard to environmental hygiene to which his predecessors devoted personal attention, but those same changes, and the successes gained in the treatment and prevention of disease, have revealed that for one of his special training and experience the call to work is no less urgent than in past generations. Prof. Grundy, therefore, while he does not omit the control of infectious diseases, has not set out to add to the number of textbooks of hygiene and sanitary practice, but deals with such matters as the influence of heredity and social environment on health and the assessment of health in the individual and in one community as compared with another. Statistics are dealt with at some length and there is a brief sketch of the history of public health and social welfare work. The work of Central and Local Government Authorities in health matters is dealt with at some length and in a way which leaves no doubt that the writer has not only knowledge but also considerable practical experience in administration.

This book can be recommended with confidence to those for whom it is intended-namely students working for the Certificate in Public Health, medical undergraduates and practitioners who wish to have a short account of the subjects with which it deals.

The author says that he had originally intended to include references and suggestions for further reading but decided to omit them-in part at least in deference to the possible desire of teachers to make their own recommendations. He has been too modest. It is to be hoped that in future editions this omission will be rectified.

\section{ILLUSTRATIONS OF BANDAGING AND FIRST AID}

By Lois OAKes, S.R.N., D.N. 4th Edition. Pp. vii +308 , with 307 illustrations. Edinburgh : E. \& S. Livingstone. 1950. 8s. 6d.

This book is well arranged in all sections with clear concise instructions, good photographs and blank pages for personal notes, which should be a great encouragement to the reader to make important observations.

Section I deals with the Triangular Bandage, and 95 pages are devoted to simple instructions and clear iliustrations. The section on Roller Bandaging has a concise introduction, which is followed again by simple instructions, and photographs of the more usually used types of bandages. Shock is dealt with very briefly, but the signs and symptoms and treatment are given, and there is a valuable conclusion on the Crush Syndrome. First Aid treatment for haemorrhage is dealt with in fair detail, and illustrated by photographs showing methods of digital and other types of pressure on pressure points. One section is devoted to the First Aid treatment of fractures, showing clearly the application of splints in this kind of work, and the conclusion of this new edition of Miss Oakes' book gives interesting information on some of the varied uses of Elastoplast.

This book should be most valuable to all those who are teaching, or learning, the art of Bandaging, both with a Triangular and with a Roller Bandage, since the subject matter is so very well illustrated by photographs.

\section{B.N.F.}

\section{A TEXTBOOK ON VENEREAL DISEASES}

By R. R. Willcox, M.B., B.S., M.R.C.S., L.R.C.P. Pp. 439, with 154 illustrations. London: William Heinemann. 1950. 32s. 6d.

Within the limits of this small volume the subject of Venereology is well covered and the information contained in it is up to date and comprehensive. Inevitably the limitations of space have determined a series of authoritative statements without the benefit of illuminating discussion, and, although not all the views expressed are generally acceptable, they are within the limits of orthodoxy. It is, however, highly undesirable that students should be given the impression that full physical examination of patients who attend clinics for venereal disease is no more than an ideal which is seldom attainable. None of these clinics is now so busy that any relaxation of standards can be condoned, and it is certainly one of the primary responsibilities of any department in a teaching hospital to allow no departure from firm principles in instructing the young. Less than justice is done to the subject of late syphilis, especially cardiovascular syphilis, even in relation to the length of the book, but the section on prenatal syphilis is excellent. The author writes well, though sometimes in a colloquial style not altogether suited to his theme.

The general standard of illustration is very high and includes many excellent photographs of lesions in negroes, in pursuance of the author's intention of supplying a 'global outlook' to his work. From the point of view of the student in this country, this is perhaps not altogether an advantage.

This is a competent textbook and is recommended. 